\title{
Diabetic diarrhea
}

National Diabetes Information Clearinghouse (NDIC)

\section{Definitions}

Constipation

Defined by National Diabetes Information Clearinghouse (NDIC)

Neuropathy

Defined by National Diabetes Information Clearinghouse (NDIC)

\section{Source}

National Diabetes Information Clearinghouse (U.S.). (2009). The diabetes dictionary. [Bethesda, Md.]: U.S. Dept. of Health and Human Services, National Institutes of Health, National Institute of Diabetes and Digestive and Kidney Diseases, National Diabetes Information Clearinghouse.

Loose stools, fecal incontinence, or both that result from an overgrowth of bacteria in the small intestine and diabetic neuropathy in the intestines. This nerve damage can also result in constipation. 